\title{
Mapping and Characterization of Agricultural Systems from Time Series of Normalized Difference Vegetation Index (NDVI) in the Northeast Area of Tadla, Morocco
}

\author{
Didi Salahddine ${ }^{1}$, Fatima Ezzahra Housni2 ${ }^{*}$, Abdessamad Najine ${ }^{1}$, Amina Wafik ${ }^{3}$, \\ Mohamed Aadraoui ${ }^{4}$, Fatima Zahra Hafiane ${ }^{5}$, Humberto Bracamontes del Toro ${ }^{6}$
}

\author{
${ }^{1}$ Valuation Laboratory and Natural Resources Management, Faculty of Science and Technology, University Sultan Moulay \\ Slimane, Beni Mellal, Morocco \\ ${ }^{2}$ Southern Region University Center, University of Guadalajara, Ciudad Guzmán, México \\ ${ }^{3}$ Dynamic Laboratory of the Lithosphere and the Genesis of Mineral and Energy Resources, Department of Geology, Faculty of \\ Science Semlalia, University Cadi Ayyad, Marrakech, Morocco \\ ${ }^{4}$ Laboratory of Geosciences and Environment, Faculty of Science and Technology, University Sultan Moulay Slimane, Beni Mellal, \\ Morocco \\ ${ }^{5}$ Unit Pollution, Ecotoxicology and Risk Sanitary Scientific Institute, Mohammed V University, Rabat, Morocco \\ ${ }^{6} \mathrm{Cd}$. Guzmán Institute of Technology, Ciudad Guzmán, México \\ Email: ^fatima.housni@cusur.udg.mx
}

How to cite this paper: Salahddine, D., Housni, F.E., Najine, A., Wafik, A., Aadraoui, M., Hafiane, F.Z. and del Toro, H.B. (2017) Mapping and Characterization of Agricultural Systems from Time Series of Normalized Difference Vegetation Index (NDVI) in the Northeast Area of Tadla, Morocco. Natural Resources, 8, 24-30. http://dx.doi.org/10.4236/nr.2017.81002

Received: December 20, 2016

Accepted: January 21, 2017

Published: January 24, 2017

Copyright $\odot 2017$ by authors and Scientific Research Publishing Inc. This work is licensed under the Creative Commons Attribution International License (CC BY 4.0).

http://creativecommons.org/licenses/by/4.0/ (c) $\underset{\mathrm{EY}}{\text { (i) Open Access }}$

\begin{abstract}
Introduction: Agriculture is the focus of sustainable development and food security in Morocco, contributing 14\% to the national economy and its socioeconomic impact depends on agro-climatic conditions and the availability of water resources. The objective of this work is to demonstrate that agriculture in Morocco, and especially in the Tadla region, is distributed according to the availability of underground water. Method: This work was carried out in the transition zone between the phosphate plateau and the plain of Tadla, a site of more than 124,000 ha. To achieve the objectives set, we used Landsat-8 OLI (Operational Land Imager) data sharpened to $15 \mathrm{~m}$. The Support Vector Machine (SVM) classifications were applied to the 10-period Normalized Difference Vegetation Index (NDVI) series. Results: It is shown that agriculture in Morocco is highly dependent on irrigation. In the classified map, it can be observed that the southern region, a zone with a semi-arid climate, which generally relies on irrigation, is very developed in agriculture, whereas in the north most of the soil is bared with cereals that mainly depend on rainfall. Conclusion: The possible water shortage in the region puts food availability in Morocco at risk of inadequacy. Food security depends on the availability of water, a natural resource at risk of extinction. Therefore, strategies to reduce
\end{abstract}


the risk of agricultural drought must be at the forefront of Moroccan policies.

\section{Keywords}

Water Availability, Landsat-8 OLI, Crop Mapping, Plain de Tadla, Morocco

\section{Introduction}

Agriculture is an important sector in Morocco, contributing 14\% of the gross domestic product (GDP). But agriculture in Morocco is also based on the availability of water resources. While water represents an insufficient resource in comparison with rapidly growing needs, the curve of water mobilization will practically cease from 2013, at a time when the population will continue to increase, at a slower pace [1].

In addition, Morocco experienced surpluses and balanced precipitation deficits. But since the 1980s, this balance has been broken and it has caused a strong imbalance resulting in severe drought [2]. This drought, the largest in a century, has led to a dramatic decline in surface and groundwater resources and agricultural productivity. This situation has undoubtedly puts in context to the food security of the nation.

Morocco's food needs are based on national production, and this refers to the concept of food self-sufficiency [3], especially in a region as the Tadla plain where agriculture is a vital and very important element. In fact, it is the primary source of employment for the region's labor force. The objective of this work is to provide precise data on the current situation of agriculture in the Tadla plain and its distribution according to the availability of water for irrigation. In this study we used a set of vegetation indices derived from Landsat 8 OLI data acquired during the agricultural year 2014-2015 for the identification and mapping of crops in the region.

\section{Study Area}

The Tadla plain covers an area of $3600 \mathrm{~km}^{2}$ and extends approximately to the north of the High Atlas Mountains. It lies between $6^{\circ} 42^{\prime} 21^{\prime \prime} \mathrm{W}$ and $6^{\circ} 16^{\prime} 03^{\prime \prime} \mathrm{W}$ longitude and $32^{\circ} 28^{\prime} 49^{\prime \prime} \mathrm{N}$ and $32^{\circ} 31^{\prime} 10^{\prime \prime} \mathrm{N}$ latitude (Figure 1), and bounded to the north by the plateau of phosphates which gradually ascends unmarked a transitional net to the east of the narrowed plain along the Oum-er-Rbia in the direction of the accredited reliefs of the Zaïan county. In the West, no geographical limit separates the Tadla from the Bahira that followed it. The lower reaches of the El-Abid River will be taken as the regional and hydro-geological boundaries of this set called Tadla. The length of the plain, as defined, reaches about 125 $\mathrm{km}$ while its maximum width in the center is about $50 \mathrm{~km}$. The average altitude varies from $350 \mathrm{~m}$ to $500 \mathrm{~m}$ with the lowest point in Sidi-Driss (hydrological station on the OumEr-Rbia: $315 \mathrm{~m}$ ) and the highest on main road 24 near Tighboula (about $750 \mathrm{~m}$ ). 


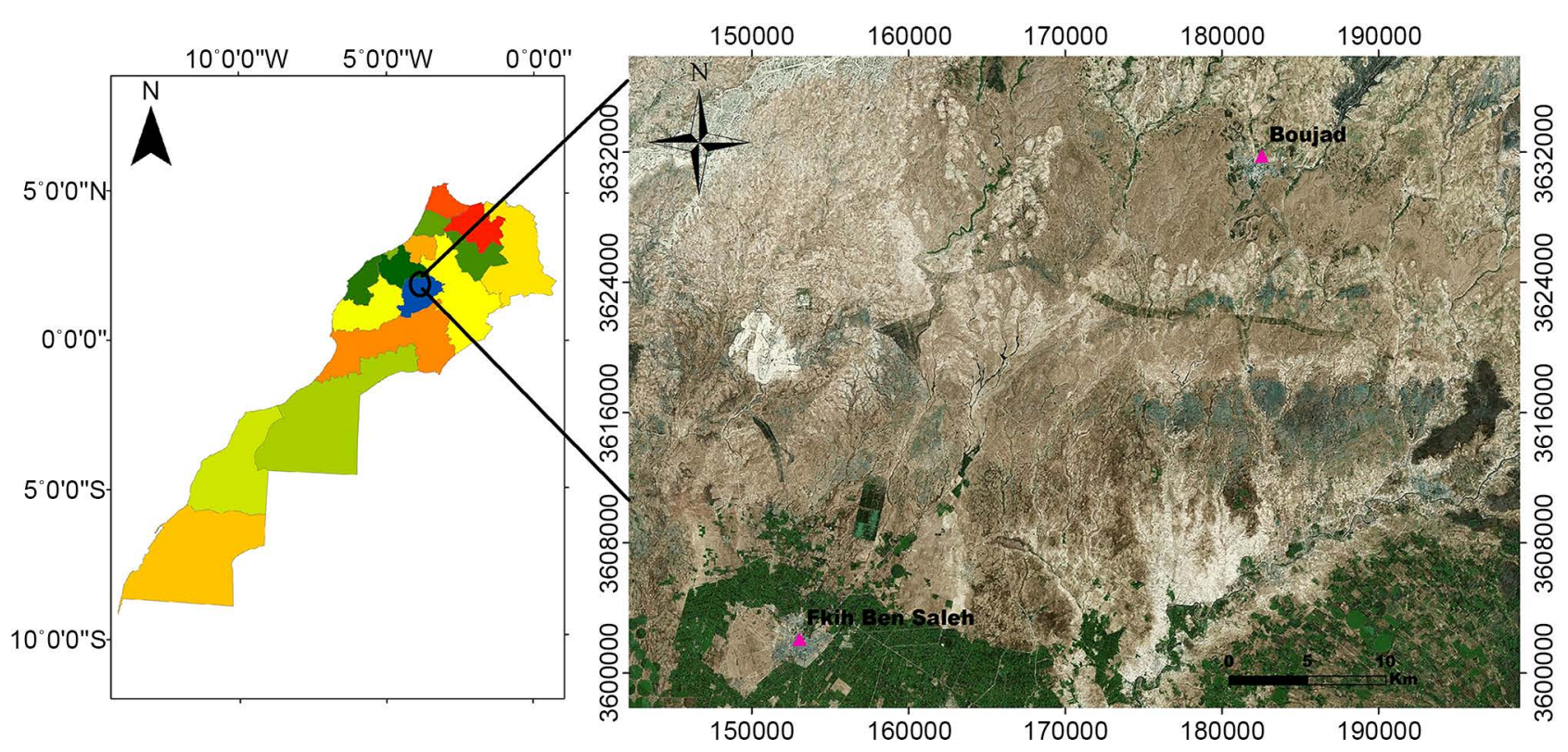

Figure 1. Study area.

\section{Methods}

This work is based on a time series of satellite images of Landsat OLI 8. We used a set of 10 images of the study area covering the period of agricultural partner (September 2014-May 2015). This allows us to have at least one image per month for the whole farm partner.

These OLI images are calibrated radiometrically and corrected from atmospheric effects and then resampled at a spatial resolution of $15 \mathrm{~m}$. The NDVI vegetation index of each image is calculated to consolidate and create a time series [4]. The spectral profiles of each culture were extracted from the image indexes on the basis of the field data. For a good accuracy of our classification, we hid the occupation of the elements of the soil that will not show interest in this study (Figure 2).

\subsection{Image Processing}

To distinguish the different cultures of the TIP, we based ourselves on their phrenological development. Thus, a time series of the NDVI vegetation index (1) is calculated from the beginning of the farm companion (September) to its end (May). This index is based on the difference in luminous energy at the level of the red and near infrared band caused by the different surfaces of the earth through the phenomenon of absorption and reflection, in particular the vegetation absorbs more than red light while reflecting much of the light in the near infrared.

The calculation of NDVI was realized using the tool "NDVI" in ENVI, specifying the input file type (Landsat OLI8) from the dropdown list and indices of the bands (red and infrared) used to the calculation (Red: 4, near IR: 5).

These vegetation indices are grouped in a single image for the extraction and comparison of the spectral profiles of the crops. Both Vector Vector Machine 


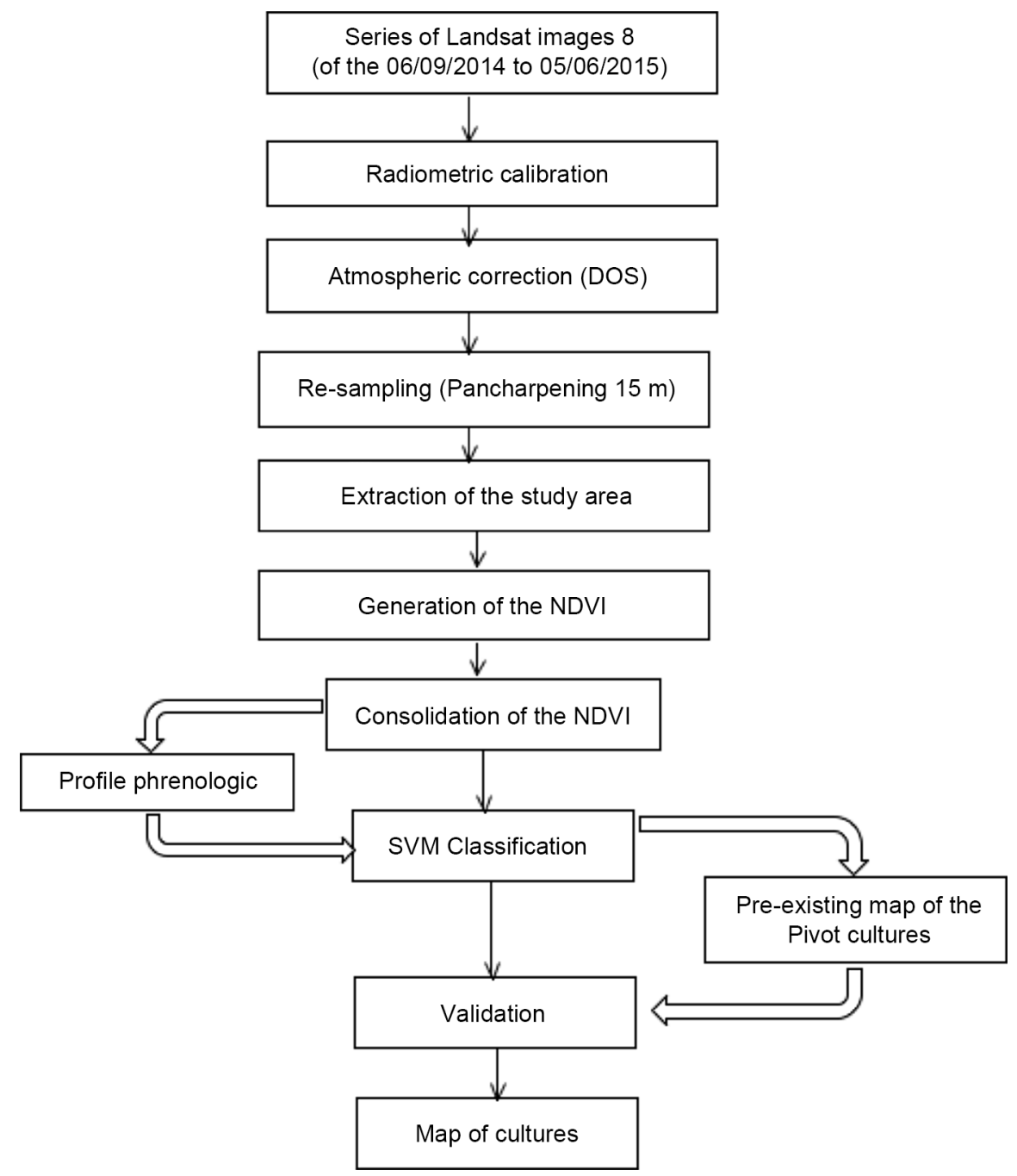

Figure 2. Schematic diagram of the used methodology.

(SVM) and Spectral Angle Mapper (SAM) classification algorithms are used to map crops.

$$
\mathrm{NDVI}=\frac{\mathrm{PIR}-\mathrm{R}}{\mathrm{PIR}+\mathrm{R}}
$$

with:

PIR: the pixel value in the near infrared band.

$\mathrm{R}$ : the pixel value in the red band.

\subsection{Classification: Support Vector Machines}

The methods of classification are the operations of image segmentation which allows determining for each pixel of the image to its class of belonging, in function of their radiometric properties [5].

Support Vector Machine (SVM) is a method of supervised classification derived from the theory of the statistical learning which often gives good results of classification of complex data and noisy. It separates the classes with a surface of decision which maximizes the margin between the classes. The surface is often 
called the hyperplane optimal, and the data points are the closest to the hyperplane are called "vectors support".

To perform the classification of the resulting image, we began by the choice of regions of interest while respecting the following rules:

- The number of pixels per class must be large enough (at least 100 pixels/class);

- For the same class regions of interest must be dispersed on the entire image, to encompass the more possible of the varieties that a type of culture can take;

- Avoid to select areas of interest combining the shaded areas and lit even if it is the same object.

Eight classes have been selected, cereal, beetroot, alfalfa, arboricultures, another culture and TSI (field without interest).The tests of separability, based on the distance from Jeffries-Matusita, between each pair of the eight classes has shown the values of separability which vary between 1.99860747 and 2, which means that our classes are well separated one compared to the other is can be used for classified the image.

\section{Results}

The classification of crop types is the basis of the phrenological properties that each image presents during the agricultural season. These properties are translated into a map through values that the NDVI records for a given crop in a given pixel during the selected season. The results obtained from the phrenological curves are presented in the form of a map of distribution of crops.

The map is divided into two areas. A zone whose crops are the following: the cultivation of the dominant beet with an area reached 49,242.465 ha, followed by arboriculture with an area of 749.99 ha and the cereal of 67,300 ha. Alfalfa is represented by an area of 22,874.80 ha. The dominance of beet sugar was explained by the request of COSUMAR in the region. And an area where the bare soil is the dominant area following the cultivation of cereals. In summary, it can be clearly seen that the zone in the south, a zone with a semi-arid climate, which relies on irrigation is very developed in agriculture, whereas in the north most of the soil is bared with cereals, a crop that depends on precipitation. Food security in Morocco is at risk, it depends on the availability of underground water, a natural resource in risk of extinction (Figure 3).

\section{Discussion}

Agriculture has always had the primary role of satisfying nutritional needs and ensuring food security at the level of individuals, groups and households as well as at the regional and national levels. According to the definition adopted by the World Food Summit, "food security exists when all people, at all times, have physical and economic access to sufficient, healthy and nutritious food to meet their nutritional needs and satisfy their preferences to ensure a healthy and active lifestyle" [6]. Food security thus comprises four aspects: availability, accessibility, use and stability [7]. Availability refers to an adequate supply of food that 


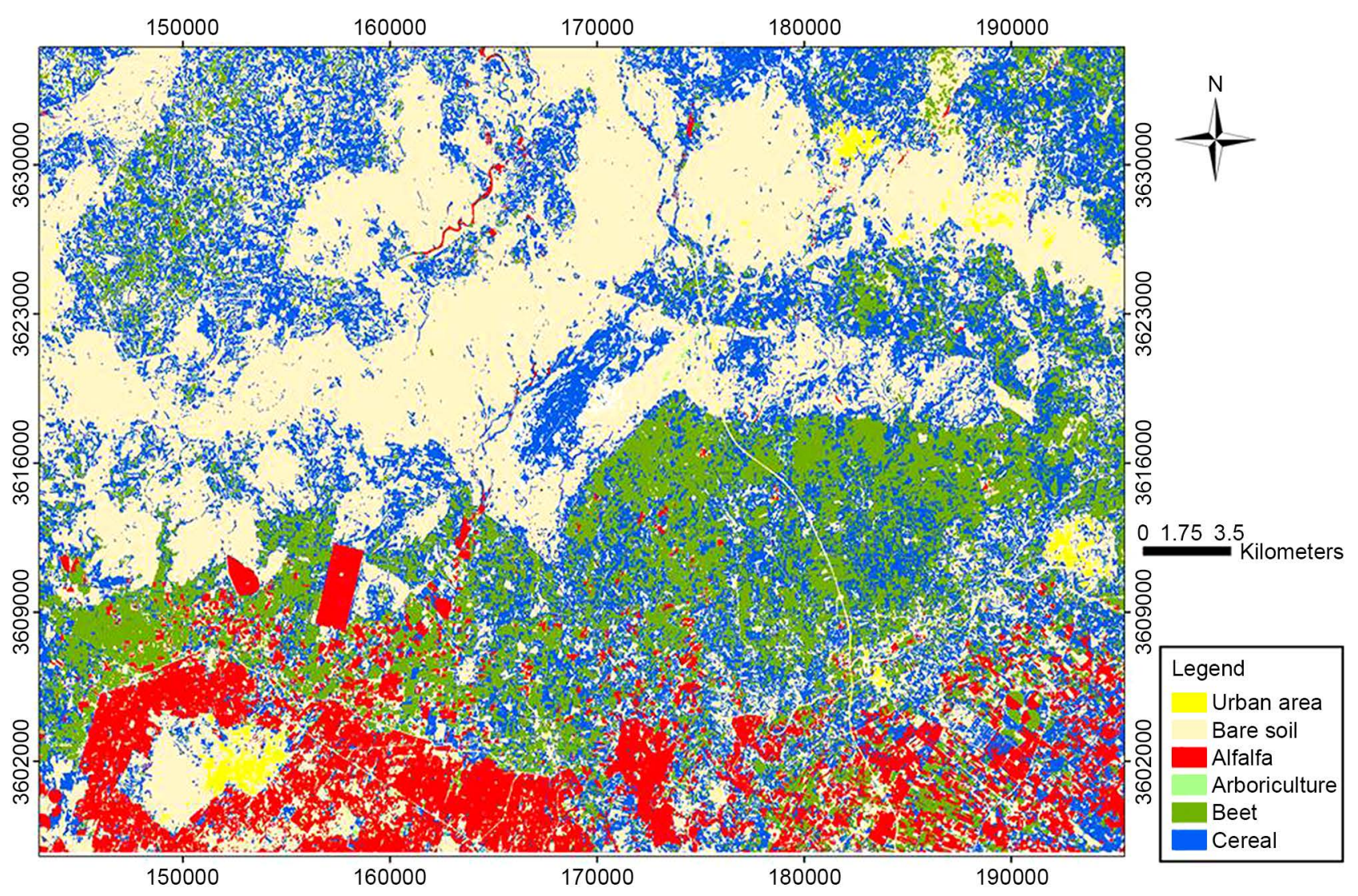

Figure 3. Time-series NDVI spectral profiles for the major crop types planted in 2014: alfalfa; sugar beet; cereal; cereal is preceded by other cultures; Arboriculture.

is secure in a sustainable way and capable of responding to population growth and changes in eating habits. Accessibility is achieved when physical and economic access to sufficient food is jointly assured. But when agriculture depends on water availability and rainfall, there is a problem of sustainability and there is talk of vulnerability to food security.

The results of this research show that the risk of water scarcity in the study area may increase under the combined pressure of drought in the northern region of the map and the demand for irrigation in the southern region. And this highlights the problem of food insecurity in a region dependent on the agricultural sector for food and economic reasons. In this context, Tadla plain is faced with a series of challenges related to the problem of water availability in the future, with vulnerabilities that could worsen considerably in the coming decades, which have the potential to make food insecurity a national priority. All this combined with other factors of social and economic vulnerability [8].

\section{Conclusion}

Agriculture is an important sector in Morocco and especially in the region of the Plein of Tadla. But when regional food availability depends on the availability of water, insufficient resources compared with growing needs, uncertainty prevails on agriculture and therefore food security. For this reason, the risk of food in- 
adequacy must be taken into account in all water management in both rainfed and irrigated agriculture. Strategies to reduce the risk of agricultural drought must be at the forefront of Moroccan policies.

\section{References}

[1] Laouina, A. (2007) L'eau au Maroc. Gestion conservatoire des eaux et des sols au Maroc, [online] RELOR-Chaire UNESCO-GN, Maroc. Redamed. http://www.h2o-environnement.com/pdf/Laouina.pdf

[2] Bahir, M., Mennani, M., Jalal, M. and Fakir, Y. (2002) Impact de la sécheresse sur les potentialités hydriques de la nappe alimentant en eau potable la ville d'Essaouira (Mogador, Maroc). Sécheresse, 13, 13-19.

[3] Nouréini Sayouti, S. and Ait El Mekki, A. (2015) Le Plan Maroc Vert et l'autosuffisance alimentaire en produits de base à l'horizon 2020. Alternatives Rurales, 3, 1-14.

http://alternatives-rurales.org/wp-content/uploads/Numero3/AltRur3PMVetAutos uffisanceAlimentaireLectEcr.pdf

[4] Herbei, M.V. and Sala, F. (2015) Use Landsat Image to Evaluate Vegetation Stage in Sunflower Crops. GroLife Scientific Journal, 4, 79-86.

http://agrolifejournal.usamv.ro/pdf/vol.IV 1/Art11.pdf

[5] Ouzemou, J.E., El Harti, A., El moujahid, A., Bouch, N., El Ouazzani, R., Lhissou, R. and El bachaoui, M. (2015) Mapping Crop Based on Phenological Characteristics Using Time-Series NDVI of Operational Land Imager Data in Tadla Irrigated Perimeter. Morocco, Remote Sensing for Agriculture, Ecosystems, and Hydrology XVII, Toulouse, 96372.

http://spie.org/Publications/Proceedings/Paper/10.1117/12.2194466

[6] World Food Summit (1996) Rome Declaration on World Food Security.

[7] Diagne, R. (2014) Sécurit'e alimentaire et libéralisation agricole. Ph.D. Dissertation, Unversité Nice Sophia Antipolis, Nice.

https://tel.archives-ouvertes.fr/tel-00998276/document

[8] Behnassi, M.M. (2014) Sécurité alimentaire et sanitaire face au changement climatique : Essai pour une stratégie d'adaptation, dans le cadre d'une gouvernance intégrée au Maroc.

http://www.ires.ma/wp-content/uploads/2015/11/securite alimentaire et sanitaire face au changement climatique - essai pour une strategie dadaptation dans 1 e cadre dune gouvernance integree au maroc.pdf 
Submit or recommend next manuscript to SCIRP and we will provide best service for you:

Accepting pre-submission inquiries through Email, Facebook, LinkedIn, Twitter, etc. A wide selection of journals (inclusive of 9 subjects, more than 200 journals)

Providing 24-hour high-quality service

User-friendly online submission system

Fair and swift peer-review system

Efficient typesetting and proofreading procedure

Display of the result of downloads and visits, as well as the number of cited articles Maximum dissemination of your research work

Submit your manuscript at: http://papersubmission.scirp.org/

Or contact nr@scirp.org 